\title{
Is Internet becoming a Major Contributor for Global warming - The Online Carbon Footprint
}

\author{
Arun Agarwal, \\ Department of ECE, ITER, \\ Siksha O Anusandhan Deemed to be University, \\ Bhubaneswar, Odisha, \\ India-751030, \\ Email: arunagrawal@soa.ac.in
}

Kabita Agarwal, Department of Instrumentation and Electronics Engineering, College of Engineering \& Technology (CET), Ghatikia, Kalinga Nagar, Bhubaneswar, Odisha, India-751030, Email: akkavita22@gmail.com

\section{Gourav Misra,}

School of Electronic Engineering, Dublin City University, Glasnevin, Dublin, Ireland, Email: gourav.misra.ima@gmail.com

\begin{abstract}
Presently $21^{\text {st }}$ century is the world of Internet, broadband, satellite TV, mobile phone etc fueled by upcoming $5 \mathrm{G}\left(5^{\text {th }}\right.$ Generation) networks. We cannot live one day without internet. More than $70 \%$ of us access the Internet on a daily basis which clearly shows the huge potential of this global system of interconnected network and how people around the world get easily addicted to it. Large E- Business and E- Marketing are the outcome of the Internet invasion in human life. But do we really care or think what effect the Internet has on our environment? The reality says in coming years with massive population around 2.5 billion people will be connected to the Internet worldwide, making Internet's energy and carbon footprint will surpass air travel. Hence Internet does not look as green as thought but responsible for Carbon dioxide $\left(\mathrm{CO}_{2}\right)$ emissions from Cloud Storage, use of various search engines and Emails. This article highlights some adverse effect of Internet on planet Earth and environment as well. Some possible remedies are also discussed for cut in our possible online carbon footprint.
\end{abstract}

\section{INTRODUCTION}

We know possible threat from advanced technology that can harm environment. Air pollution form industries, water pollution, heat, noise pollution are some examples that results by usage of technology [1]. In addition to this the used computers and electronics are discarded when they are damaged or become outdated. It may be noted that these huge electronics hardware are composed of such kind of raw materials that if we fail to recycle it properly, there is $100 \%$ possible chance of releasing harmful toxic chemicals into the earth, which will definitely spoil both our water and food supply for many years to come.

Apart from these here comes the most famous Internet without which people on this earth cannot live for 1 hour also. Imagine you forgotten the name of the song? Need to book a flight, train ticket, online shopping, and book a seat in 
Journal of Information Technology and Digital World (2020)

Vol.02/ No. 04

Pages: 217-220

https://www.irojournals.com/itdw/

DOI: https://doi.org/10.36548/jitdw.2020.4.005

restaurant, room in hotel, order pizza. Answer is Google it. But during the process, this use of internet each time leaves a carbon footprint. Are we aware of this online carbon footprint? Had we thought our internet searches are bad for the planet?

Further with the rise of Internet Digital waste has grown enormously over the last decade in the form of data storage, such as e-mails, pictures, audio and video files, etc. which now the hottest filed in online Commerce industry called Big Data [2].

\section{THE REALITY FACTS AND STATISTICS}

As per the $[1,2]$ the use internet releases around $300 \mathrm{~m}$ tones of $\mathrm{CO}_{2}$ per year which is equivalent to burning of gas, oil and coal alone in Turkey or Poland. Also, this data is same as every person in the UK flying twice to and for America. This carbon footprints due to internet cannot be reduced instantly because of its complex nature. As this huge worldwide interconnected network involves millions or even billions of computers/laptops/iPad/Smart phones owned by countless people and vast companies.

This enormous data generation needs to be handled by big servers in data centers which in turn needs lots of electricity mainly for the air conditioning the servers to avoid overheating. It is projected in a study [2] that, by 2030 the ICT's footprint is expected to increase by $60 \%$.

Other findings [1] say that 20mg of CO2 are generated every second whenever someone is using a simple website. The internet's annual carbon footprint is same as carbon dioxide released by aviation industry in a year. This due to the fact that internet relies on millions of physical servers in data centers around the world, and miles of undersea cables and routers- all of which need a lot energy to run. Most of that energy comes from burning fossil fuels, which emit carbon dioxide into the air. Google enjoys $40 \%$ share in internet's carbon footprint since it processes 3.5 billion searches a day [3, 4]. As an approximation an average car driven for $1 \mathrm{~km}$ is same as 1000 Google searches. Each time we are browsing a simple website we approximately generate $20 \mathrm{mg}$ of $\mathrm{CO} 2$ every second, which is roughly same as 1 million $\mathrm{mg}$ of carbon emission generated by an air-freighted orange [5]. The basic principle underlying more greenhouse gas emissions are continuous working of thousands of servers, which require considerable amount of energy to process trillions of data every minute.

A recent finding says an email has around $4 \mathrm{~g}$ of estimated carbon footprint. I few ask one question, "What Google as a company emits?" the answer would be 2.9 million metric tons of $\mathrm{CO} 2$, according to one of the Google's 2016 environmental report. This equivalent to annual greenhouse gas emission of 620,000 cars!

\section{SIDE EFFECTS OF INTERNET ON HUMAN BEING}

The youths are majority victims under this category which are dominated by Students and teenagers. The most common everyday negative/ill effects of frequent Internet use are listed below [6]:

a) Wastage of precious time.

b) Ignorance of family members.

c) Decreasing Physical activity leading to Obesity.

d) Downfall in Face to Face Communication and hence one to one physical talking.

e) Disruption in Privacy.

f) Dependence on internet and lack of Creativity.

g) Cybercrime or Cheating

h) Online bullying or harassment.

i) Accessing inappropriate websites causing wrong mental development.

j) Addiction to Internet comparable with drug addiction leading to depression.

k) Insomnia as sleeping time donated to internet surfing. This also affects mental health in long run.

ISSN: 2582-418X 
Journal of Information Technology and Digital World (2020)

Vol.02/ No. 04

Pages: $217-220$

https://www.irojournals.com/itdw/

DOI: https://doi.org/10.36548/jitdw.2020.4.005

\section{POSSIBLE SOLUTIONS TO CUT ONLINE CARBON FOOTPRINT}

From above discussion it may seem that the whole IT industry is spoiling our planet Earth and they are not thinking about the ill effects of Internet. But in reality large organizations like Google has awaken and taken major steps to cut carbon footprint through investing roughly $\$ 1$ billion in renewable energy methods recently. It may be noted that when compared to ordinary/typical data centers, Google data centers are more efficient and utilize about $50 \%$ less energy. Now, Yahoo also has come forward in this positive direction becoming Newsweek's top 10 lists of greenest companies in America by deploying energy efficient data centers, and their sponsored site Yahoo! Green. One another possible solution which large companies are practicing is the use of Cloud Computing.

Now we highlight some of the easy measures to reduce online carbon footprint which can be done by a Common man in this planet using Internet as follows:

a) Making use of a Smartphone or Tablet as far as possible as they consume less energy.

b) Making a habit of unplugging the chargers from device on the event of fully charged.

c) Switching off the Computer when not required. No sleep mode as it still burns energy.

d) By storing your maximum data in green cloud providers or on those who run on renewable energy.

e) By changing our Email habits, i.e., lesser use of reply to all, unsubscribing from all newsletters that are irrelevant, cutting unnecessary downloads etc.

f) Limiting the use of WhatsApp.

g) Overall making sure to use internet when in need.

\section{CONCLUSION}

Though we discussed a lot about cons of internet but the reality says it is indeed the backbone of today's communication where it has brought people closer and is a major source of vital information for students' community. The internet saves enormous amount of paper usage and hence tress, which in turn reduce carbon dioxide in the atmosphere. Remote working people use Skype for presentations instead of physically traveling. This reduces unwanted transport and therefore saves fossil fuels and cut $\mathrm{CO}_{2}$ emissions as well.

\section{KEY REFERENCES:}

1. https://www.onegreenplanet.org/animalsandnature/is-your-internet-use-destroying-the-environment/

2. https://www.theguardian.com/environment/2010/aug/12/carbon-footprint-internet

3. www.climatecare.org

4. www.internetlivestats.com

5. https://www.triplepundit.com/2012/09/internet-environment/

6. http://vkool.com/negative-effects-of-internet/

Information Technology \& Digital World 
Journal of Information Technology and Digital World (2020)

Vol.02/ No. 04

Pages: $217-220$

https://www.irojournals.com/itdw/

DOI: https://doi.org/10.36548/jitdw.2020.4.005

\section{Authors Biography}

\section{Author - 1- Arun Agarwal}

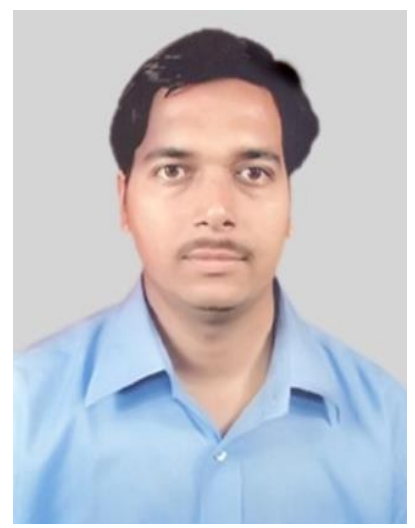

Arun Agarwal has more than 14 years of professional, research, and teaching experience in wireless digital communication system. He is working as an Assistant Professor in ECE department at ITER (Faculty of Engineering and Technology), Siksha 'O' Anusandhan Deemed to be University, Bhubaneswar, Odisha, India. He completed B. E (2003) in Electronics \& Telecommunication Engineering from Padmanava College of Engg., Rourkela and M. TECH (2010) in Telematics and Signal Processing from NIT, Rourkela, Odisha. Currently he is pursuing PhD from AMET University, Tamil Nadu, Chennai, India. His field of interest includes mobile wireless communication, MIMO-OFDM, LTE-A, 5G networks and signal processing. He has over 50 research articles published in journals, national and international conferences. $\mathrm{He}$ is member of IEEE \& life member of ISTE, IETE, IACSIT, IEI professional society. $\mathrm{He}$ is also member of Editorial Board \& Reviewer of many International Journals. He has also served as a TPC of many Springer and IEEE International Conferences. 